\title{
Interspecific and Intersexual Differences in the Chemical Composition of Floral Scent in Glochidion Species (Phyllanthaceae) in South China
}

\author{
Daihong Huang, ${ }^{1}$ Fuchen Shi, ${ }^{1}$ Minwei Chai, ${ }^{2}$ Ruili $\mathrm{Li}^{2}{ }^{2}$ and Houhun $\mathrm{Li}^{1}$ \\ ${ }^{1}$ College of Life Sciences, Nankai University, Weijin Road 94, Tianjin 300071, China \\ ${ }^{2}$ Key Laboratory for Urban Habitat Environmental Science and Technology, School of Environment and Energy, \\ Shenzhen Graduate School of Peking University, Shenzhen 518055, China \\ Correspondence should be addressed to Fuchen Shi; fcshi@nankai.edu.cn and Ruili Li; liruili@pkusz.edu.cn
}

Received 19 August 2015; Revised 14 October 2015; Accepted 15 October 2015

Academic Editor: Hassan Arida

Copyright (C) 2015 Daihong Huang et al. This is an open access article distributed under the Creative Commons Attribution License, which permits unrestricted use, distribution, and reproduction in any medium, provided the original work is properly cited.

\begin{abstract}
Plants of the Glochidion (Phyllanthaceae) genus are pollinated exclusively by host-specific Epicephala (Gracillariidae) moths. Floral scent has been thought to play key role in the obligate pollination mutualism between Glochidion plants and Epicephala moths, but few studies have been reported about chemical variation in floral volatiles of Glochidion species in China. Floral volatiles of male and female flowers of five Glochidion species in south China were collected by dynamic headspace absorption technique and then were chemically analyzed by using gas chromatography-mass spectrometry. A total of 69 compounds were identified from floral scents of five investigated species. Glochidion hirsutum and G. zeylanicum showed no qualitative differences in floral scent, whereas there were clear variations of floral scent among other species (G. eriocarpum, G. daltonii, and G. sphaerogynum) and also they distinctly differed from these two species. Male flowers emitted significantly more scent than female flowers. Glochidion plants exhibited qualitative and quantitative differences in floral scent between two sexes of flowers. The findings suggest that the volatile variation of floral scent among Glochidion species reflects adaptations to specific pollinators. Sexual dimorphism in floral scent has evolved to signal alternative rewards provided by each sex to Epicephala moths.
\end{abstract}

\section{Introduction}

Mutualism is cooperative interactions in which each associated species benefits from its partner [1,2]. Obligate pollination mutualism between plants and their seed-parasitic pollinators is known as one of the most specialized plantinsect interactions [3-6], where insects usually exclusively pollinate for the host flowers in which they lay eggs; in turn the hosts offer seeds to feed pollinator larvae [7, 8]. The classical examples of such nursery pollination systems are the fig-fig-wasp [4] and yucca-yucca-moth interactions [6]. Moreover, the obligate pollination mutualism between Epicephala moths (Gracillariidae) and tribe Phyllantheae plants (Phyllanthaceae) has been also documented, including the associations of Epicephala moths with Glochidion,
Phyllanthus, Breynia, Flueggea, and Sauropus species [5, 911]. Glochidion, the largest genus in the tribe Phyllantheae (Phyllanthaceae), contains around 318 species of monoecious shrubs/trees mainly distributed in tropical Asia, Pacific islands, Australia, and Madagascar [12], a few also in tropical America and Africa, and in China ranging from southwest China to Taiwan [13]. All Glochidion plants rely on speciesspecific female moths of the genus Epicephala for obligate pollination $[5,14]$. At night, a female moth actively collects pollen grains from the host male flower using unique proboscises equipped with numerous hairs and then deposits them on the female flower and subsequently lays an egg using the specialized acicular ovipositor. The hatched larva consumes only a subset of the maturing seeds within a single fruit to complete the development and drill out of the fruit. The rest 
of the seeds ensure that the hosts reproduce their offspring [5].

The most intriguing characteristics among GlochidionEpicephala mutualism are extremely high taxonomic diversity and species specificity of both plants and moths $[5,7$, 14]. Pollinators' encounter with host plants is the key step in these specialized pollination interactions. Floral scents are complex blends of volatile organic compounds, which have been thought to be crucial chemical signals guiding obligate nocturnal moths to locate host plants in Glochidion-Epicephala associations. Interspecific variations of floral scents among Glochidion plants are essential for maintaining species specificity of Glochidion-Epicephala mutualism [1517], and Epicephala moths are also capable of discriminating their hosts using floral odor $[16,18]$.

So far, studies on Glochidion-Epicephala mutualism have focused on pollination biology and insect taxonomy in China $[19,20]$ and Japan $[5,9,10]$. However, little is reported about the chemical composition of floral scents from Glochidion plants in China. Recently, two pollination relationships between Glochidion and Epicephala were found in south China: (1) one Epicephala species exclusively pollinates one Glochidion species (G. eriocarpum, G. daltonii, and G. sphaerogynum) (unpublished data); (2) one Epicephala species jointly pollinates two Glochidion species (G. hirsutum and G. zeylanicum) [12]. For maintaining extremely high species specificity of Glochidion-Epicephala mutualism, floral scents may differ among Glochidion species pollinated by different Epicephala moths, while Glochidion species pollinated by the same Epicephala moth should produce similar floral signals. Therefore, it is speculated that variations in floral scent among different Glochidion species should reflect differences in Epicephala moth species with which the plants are associated.

The dioecious plants pollinated by animals often, but not always, transmit similar floral signals between the male and female flowers to attract the same pollinator to complete conspecific pollen transfer [21-23]. An implicit assumption in the fact is that pollinators use similar signals to seek the similar reward from flowers of both sexes (e.g., floral nectar) [21]. Conversely, if the plants offer different rewards to the specific pollinators on the male flowers (e.g., pollen) and female flowers (e.g., ovule), floral characters (e.g., shape, visual, and odor) may be selected to diverge between both sexes of the flowers to signal alternative rewards [23, 24]. Interestingly, in Epicephala-pollinated Phyllanthaceae plants, there was sexual dimorphism of floral scents between male and female flowers, which is in contrast to scent from non-Epicephala-pollinated Phyllanthaceae [18, 25]. Female Epicephala moths pollinate the host plants, involving distinctly different behaviors on male and female flowers: pollen collection from male flowers and then pollen deposition and oviposition on female flowers [5, 9-11]. Therefore, it was thought that sexual dimorphism in floral scent of Epicephala-pollinated Phyllanthaceae plants has evolved to signal alternative floral rewards provided by each sex to Epicephala moths [18]. In our field observations on Glochidion-Epicephala mutualism, Epicephala moths also exhibited similar high specific pollination behaviors on male and female flowers as found in previous studies [5, 9-11].
Based on the above discussion, we hypothesized that, in mutualism recently found in China between Glochidion and Epicephala, (1) variations in floral scent composition among five Glochidion species may reflect adaptations to species-specific pollinators with which the host plants are associated and (2) Glochidion plants should be selected to produce different fragrance blends between the male and female flowers to induce Epicephala moths to get the different rewards from flowers of each sex. Consequently, the floral volatiles of both male and female flowers in five Glochidion species were collected, respectively, by the headspace adsorption technique and chemically characterized using gas chromatography-mass spectrometry (GC-MS). Then, nonmetric multidimensional scaling (NMDS) was performed to investigate interspecific variations and intersexual differences in floral scent composition of five Glochidion species in south China.

\section{Methods and Materials}

2.1. Plants. Five studied Glochidion species, including G. eriocarpum, G. daltonii, G. sphaerogynum, G. hirsutum, and G. zeylanicum, generally inhabit forest margins of tropical and subtropical forests in south China [13]. Of these five species, G. hirsutum and G. zeylanicum grow together and occurred in sympatry at the study sites. In contrast, the other three species occurred in other different study sites and so their distributions did not overlap (Figure 1).

Glochidion species investigated in this study are monoecious trees with inconspicuous green female flowers and yellow male flowers which are aggregated on the axils of the leaves (Figure 2). Female flowers are sessile, more or less budlike, and appear to have specialized morphology: the style fused into a column at the trip with a small opening where the stigma is concealed in the inner surface, which makes it difficult to touch for flower visitors other than Epicephala moths. Male flowers are pedunculate with unfolded five or six sepals to expose the stamen. Glochidion flowers are small and are fragrant to the human nose only during the evening, and the floral scents of Glochidion species may be one of the key signals attracting nocturnal obligate pollinator Epicephala moths.

The five Glochidion species are associated with four Epicephala moth species in our study regions [20,26]. Among these five species, G. hirsutum and G. zeylanicum share similar morphology except that the trichomes on the epidermis are produced in the female flowers of G. zeylanicum rather than that of G. hirsutum (Figures 2(g) and 2(i)) and pollinated by the same Epicephala species, E. bipollenella. However, the other three species are, respectively, pollinated by other species-specific Epicephala moths.

2.2. Floral Scent Collections. To analyze floral scent profiles of both male and female flowers of five Glochidion species, odor collections were performed using the dynamic headspace adsorption technique [27]. The details of the study sites, dates, and sample sizes are given in Figure 1 and Table 1. Before scent collection, specimens of each studied species were gathered 
TABLE 1: Study sites, dates, and sample sizes of five Glochidion species headspace collections.

\begin{tabular}{lcccrc}
\hline \multirow{2}{*}{ Species } & \multirow{2}{*}{ Study sites } & \multirow{2}{*}{ Dates } & \multicolumn{2}{c}{ Samples } & \multicolumn{2}{c}{ Number of flowers } \\
& & & Male & Female & Male \\
\hline G. eriocarpum & Pingxiang, Guangxi & Mar.-Apr. 2013 & 3 & 4 & $300-400$ \\
G. daltonii & Sichuan, Panzhihua & Apr.-May 2013 & 7 & 6 & $200-500$ \\
G. sphaerogynum & Wuzhishan, Hainan & Dec. 2013-Jan. 2014 & 4 & 4 & $500-1000$ \\
G. hirsutum & Fujian, Xiamen & Sep.-Oct. 2013 & 3 & 3 & $100-200$ \\
G. zeylanicum & & & & $300-350$ \\
\hline
\end{tabular}

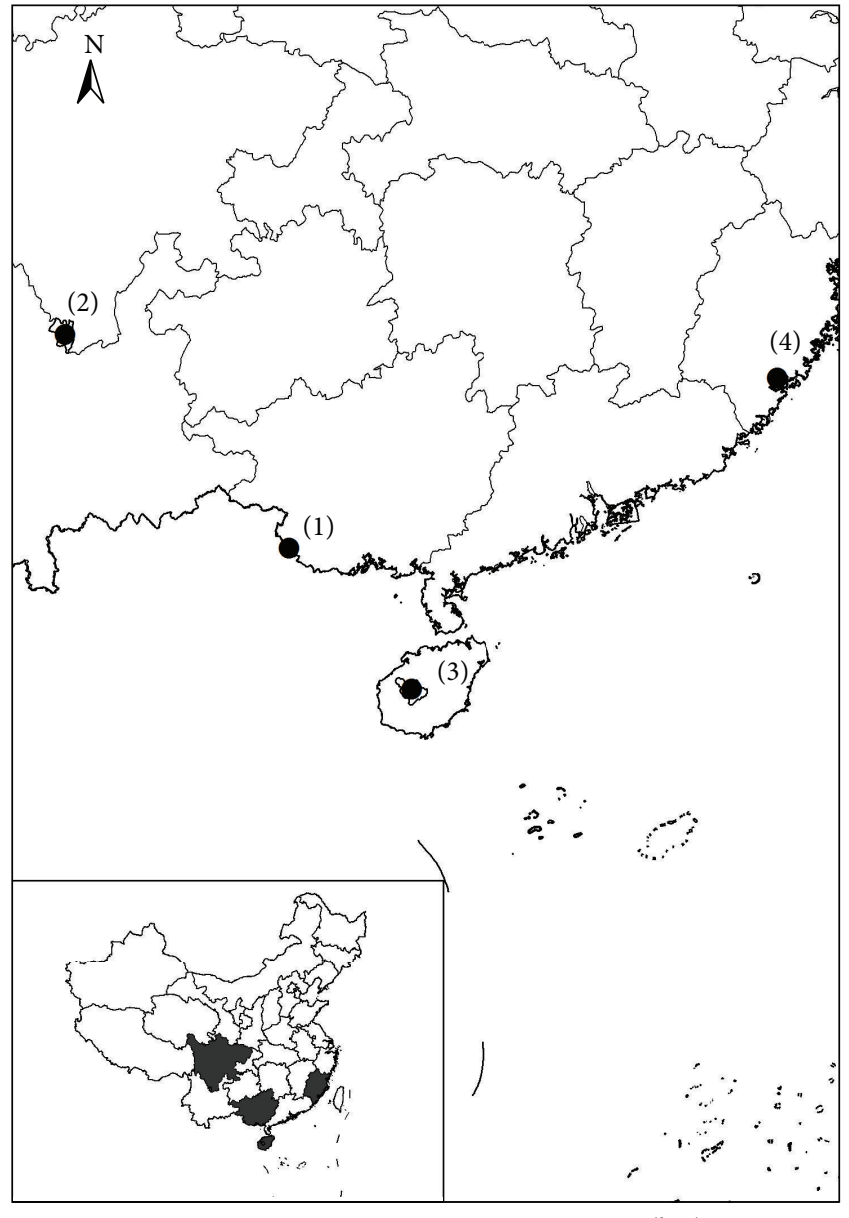

$(\mathrm{km})$
(1) G. eriocarpum
(4) G. hirsutum
G. zeylanicum
(2) G. daltonii
(3) G. sphaerogynum

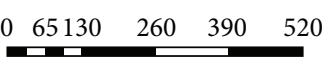

FIGURE 1: Study sites of five Glochidion species from south China in this study.

to save in our lab as a voucher. Female and male flowers of each species were removed from plants and put separately into the polyvinyl acetate bags for floral scent collection (Toppits; Melitta Scandinavia AB, Klippan, Sweden). Air was purified by active charcoal (Sigma-Aldrich, USA) and then introduced into the bag through Teflon tubes (VICI Jour Ltd., Sweden) with a mini air-pump. Air-containing floral volatiles were sucked through the small glass tube (outer diameter
$6 \mathrm{~mm}$, length $75 \mathrm{~mm}$ ) filled with 100 and $50 \mathrm{mg}$ of TenaxTA (mesh 60/80; Sigma-Aldrich) to adsorb floral scent. Meanwhile, air samples were also collected from empty bags as controls to identify possible background contamination during volatile collections. The flow rate of air in the inlet and outlet of the sample bag was set to $400 \mathrm{~mL} \mathrm{~min}^{-1}$. Odor collection was done at ambient temperature $\left(25-28^{\circ} \mathrm{C}\right)$ indoors and continued for $3 \mathrm{~h}$ during the night. After collection, the filters were sealed with Parafilm and then wrapped with silver paper and stored at $-20^{\circ} \mathrm{C}$ until used for analysis.

Before analysis, the collected floral scents in Tenax-TA filters were eluted with $2 \mathrm{~mL}$ of hexane into brown glass vials, and then $10 \mu \mathrm{L}$ of $\mathrm{n}$-Eicosane $\left(1 \mathrm{mg} \mathrm{mL}^{-1}\right)$ was added as the internal standard to calculate release amount of individual scent compounds. The eluate containing the floral volatiles was carefully concentrated down to $100 \mu \mathrm{L}$ under $\mathrm{N}_{2}$ flow.

2.3. Chemical Analysis of Floral Scents. To analyze chemical composition of floral scents, the headspace samples of Glochidion species were subjected to GC-MS, using an HP 6890 gas chromatograph (Agilent Technologies Inc., USA), and coupled with an HP 5975 mass spectrometer (Agilent Technologies Inc.). The GC was equipped with HP-5MS capillary column $(30 \mathrm{~m} \times 0.25 \mathrm{~mm} \times 250 \mu \mathrm{m}$ film thickness; Agilent Technologies Inc.). Helium was used as the carrier gas at a flow rate of $1.0 \mathrm{~mL} \mathrm{~min}^{-1}$. For each sample, $2 \mu \mathrm{L}$ was injected in a split mode (the split ratio was 1:1) for $1 \mathrm{~min}$ with an injector temperature of $250^{\circ} \mathrm{C}$. After injection, the oven temperature was programmed to be kept at $40^{\circ} \mathrm{C}$ for $5 \mathrm{~min}$, followed by an increase of $3^{\circ} \mathrm{C} \mathrm{min}{ }^{-1}$ to $150^{\circ} \mathrm{C}$ and $10^{\circ} \mathrm{C} \mathrm{min}^{-1}$ to $200^{\circ} \mathrm{C}$, where it was held for $5 \mathrm{~min}$. Mass spectra were recorded at $70 \mathrm{eV}$ in the electron impact ionization mode, and the ionic source temperature was $230^{\circ} \mathrm{C}$.

Compound identification was carried out using the NIST 08 mass spectral libraries and further confirmed by comparison of retention indices with those reported in the literature $[28,29]$, the NIST Chemistry WebBook (http://webbook.nist.gov/chemistry/) [30], and The Pherobase (http://www.pherobase.com/) [31]. Compounds in the samples presented at higher or similar percentages in controls were considered as contaminants and excluded from the analysis. For the quantities of compounds, the amount of each volatile compound was calculated as its peak area relative to the total peak area on gas chromatograms.

2.4. Statistical Analyses. Unpaired $t$-test was used to determine if there were significant differences in the total amounts 


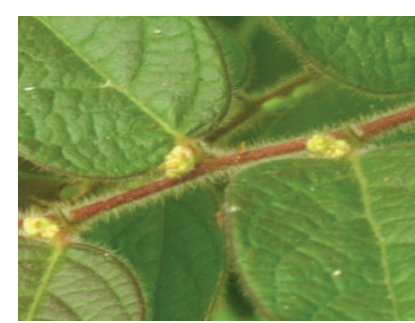

(a)

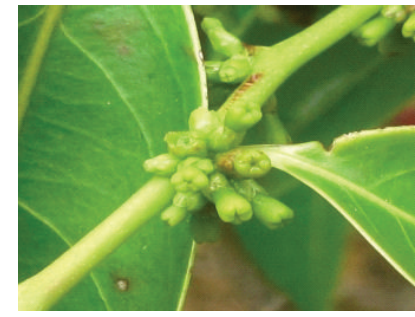

(c)

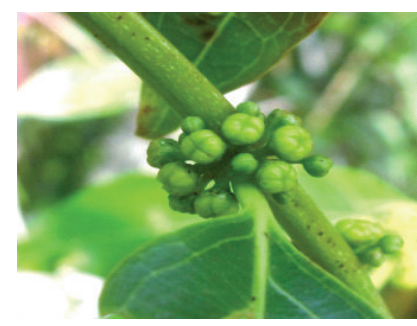

(e)

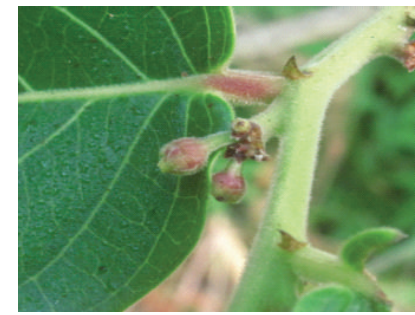

(g)

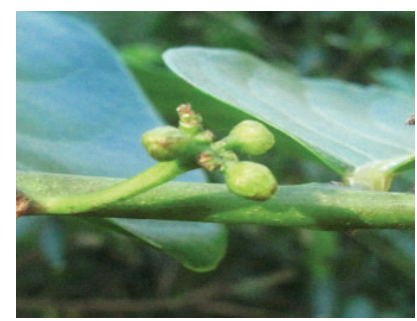

(i)

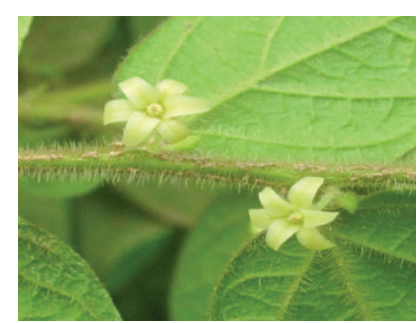

(b)

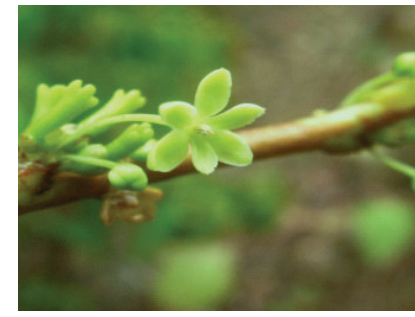

(d)

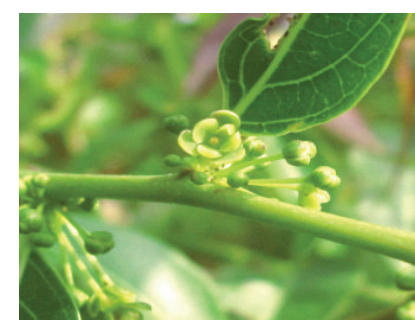

(f)

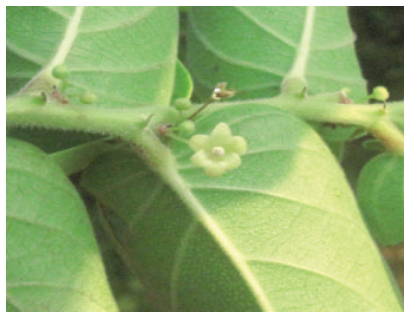

(h)

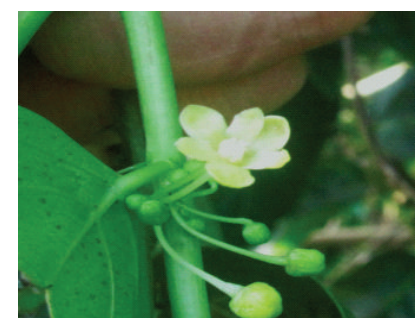

(j)

FIgURE 2: Flowers of the five Glochidion species in this study. Female of G. eriocarpum (a), G. daltonii (c), G. sphaerogynum (e), G. hirsutum (g), and G. zeylanicum (i). Male flowers of G. eriocarpum (b), G. daltonii (d), G. sphaerogynum (f), G. hirsutum (h), and G. zeylanicum (j).

of floral scents emitted from single male and female flower of each species; one-way ANOVA was used to test the significant differences between relative content of four chemical classes compounds with each species; NMDS is a nonparametric dimension reduction technique that carries on without the assumption of linear response and escapes many of the distortions of eigenvector techniques [32]. In order to analyze the interspecific variation and sexual dimorphism of floral scent composition in Glochidion species, NMDS was first performed to visualize dissimilarities among the headspace samples of floral scents using Canoco 5.0 for Windows and then the Mann-Whitney $U$ test was used to 
test for significant differences among them. All figures were plotted with Graphpad Prism 5.0.

\section{Results}

3.1. Chemical Composition of Floral Volatiles. The chemical compositions of floral volatiles of both male and female flowers of five investigated Glochidion plants are summarized in Table 2. The compounds were categorized into four chemical classes by biosynthetic pathways $[33,34]$ : aliphatics, monoterpenes, sesquiterpenes, and aromatics.

A total of 69 volatile compounds were detected and identified from the five species, comprising 35 terpenoids (12 monoterpenes and 23 sesquiterpenes), 21 aliphatics, and 13 aromatics. Dominant compound classes were monoterpenes and sesquiterpenes. Of the 69 detected compounds, 46 were found in at least two species, while only 10 were commonly shared by all five species. Notably, two compounds, (Z)-3hexen-1-ol (compound 2) and (E)- $\beta$-ocimene (compound 25 ), occurred frequently in both male and female flowers of all species; and 23 (G. zeylanicum) to 48 (G. daltonii) compounds were found in each species. There was a high degree of overlap in floral compounds produced between G. hirsutum and G. zeylanicum, and only one compound, (E)-linalool oxide (furanoid) (compound 27), was found only in G. zeylanicum; thus the two species were thought to have similar composition pattern in floral volatiles. If $G$. hirsutum and G. zeylanicum were considered as one species, 5-6 compounds were unique to a single species. For instance, butyl butyrate (compound 5), (Z,Z,Z)-1,5,9,9-tetramethyl1,4,7-cycloundecatriene (compound 47), $\gamma$-elemene (compound 38), $\beta$-humulene (compound 42), and mellein (compound 69) were species-specific compounds for G. sphaerogynum, while (E,E)-2,6-dimethyl-1,3,5,7-octatetraene (compound 30), $\alpha, \beta$-copaene (compounds 39,34$)$, benzeneacetaldehyde (compound 58), and methyl benzoate (compound 59) were only produced in both G. hirsutum and G. zeylanicum and not in any other species. Most of the compounds were detected in relatively small amounts (between trace amounts and $<10 \%$ ) in flowers of each sex; the floral scent of each species studied was dominated by only 14 compounds in relatively high amounts as follows. In male flowers, G. eriocarpum was dominated by $\beta$-elemene (compound 35, 28.22\%), $\alpha$-selinene (compound 52, 16.09\%), $\beta$-selinene (compound 49, 14.54\%), and longiborneol (compound $56,14.16 \%)$; $G$. daltonii was dominated by $(E, E)-\alpha-$ farnesene (compound 54, 40.3\%) and $\beta$-elemene (compound 35, 27.13\%); G. sphaerogynum was dominated by linalool (compound 28, 59.75\%); G. hirsutum and G. zeylanicum were dominated by (E)-2-nonenal (compound 11, 30.6 and 23.5\%, resp.), (E,Z)-2,6-nonadienal (compound 31, 19.19 and 17.46\%, resp.), and (E)-2-nonen-1-ol (compound 12, 14.14 and 11.17\%, resp.). In female flowers, $G$. eriocarpum was dominated by (E)- $\beta$-ocimene (compound 25, 42.6\%) and (E)-2-hexen-1-ol (compound 3, 11.55\%); G. daltonii was dominated by linalool (compound 28, 44.85\%); G. sphaerogynum was dominated by linalool (compound $28,23.61 \%$ ), $\beta$-elemene (compound 35, $22.64 \%$ ), $\alpha$-selinene (compound 52, 12.03\%), and $\beta$-selinene (compound 49, 11.87\%); G. hirsutum and G. zeylanicum were dominated by $(E)$ - $\beta$-ocimene (compound 25, 59.4 and $62.74 \%$, resp.) and linalool (compound 28, 12.43 and $12.26 \%$, resp.).

The relative contents of four chemical classes of compounds from male and female flowers among the respective five species are shown in Figure 3. For male flowers, the floral scents emitted by the five species could be divided into four groups: G. eriocarpum (86.65\%) and G. daltonii (94.76\%) dominated by sesquiterpenoids; G. sphaerogynum (67.87\%) dominated by monoterpenoids; aliphatics with monoterpenoids in G. hirsutum (56.46 and 23.33\%, resp.); aliphatics with aromatics in G. zeylanicum (38.56 and 29.85\%, resp.). Likewise, the floral scents produced by female flowers of the five species were also divided into four groups: G. eriocarpum (51.73 and $32.68 \%$, resp.) dominated by monoterpenoids with aromatics; G. sphaerogynum (67.95\%) dominated by sesquiterpenoids; G. hirsutum (73.71\%) and G. zeylanicum (78.02\%) dominated by monoterpenoids. The findings indicated degrees of difference in chemical composition of floral scents among the five species.

In addition, there were clear differences in scent composition pattern of four different chemical classes between the male and female flowers of the five species. For example, in $G$. daltonii, the major components of male flowers were sesquiterpenoids, whereas those of the female flowers were monoterpenoids.

3.2. Interspecific Variation of Floral Scents. The NMDS analysis of floral scent profiles of both male and female flowers of the five Glochidion species is shown in Figure 4. For male flowers, the floral samples were divided into four groups: $G$. daltonii; G. eriocarpum; G. sphaerogynum; and G. hirsutum and G. zeylanicum. The floral samples of G. hirsutum and G. zeylanicum greatly overlapped $\left(\chi^{2}=0.048, P=0.827\right.$ ), whereas those of the other three species were evidently distinguished from each other, as well as being obviously separated from G. hirsutum and G. zeylanicum $\left(\chi^{2}=17.50\right.$, $P=0.001$ ). A similar separation pattern was also observed in the floral samples of female flowers (G. hirsutum and $G$. zeylanicum: $\chi^{2}=1.19, P=0.275$; G. daltonii, G. eriocarpum, G. sphaerogynum and G. hirsutum, or G. zeylanicum: $\chi^{2}=$ $12.752, P=0.005)$. Altogether, the results suggested that $G$. hirsutum and G. zeylanicum had no difference in floral scent composition, whereas there were clear variations in floral scent among the other three species and it greatly differed from these two species.

3.3. Emission of Floral Scents. Total emissions of floral scents emitted by male and female flowers of the five Glochidion species are shown in Figure 5. In all investigated species, a male flower produced on average significantly greater amounts of scents than a female flower (G. daltonii: $t=9.18$, $P<$ 0.001; G. eriocarpum: $t=11.61, P<0.001 ; G$. sphaerogynum: $t=3.63, P<0.05$; G. hirsutum: $t=7.88$, $P<0.001 ;$ G. zeylanicum: $t=12.35, P<0.001)$. In addition, regardless of male or female flower, G. hirsutum and G. zeylanicum produced similar amounts of floral odor. Altogether, 


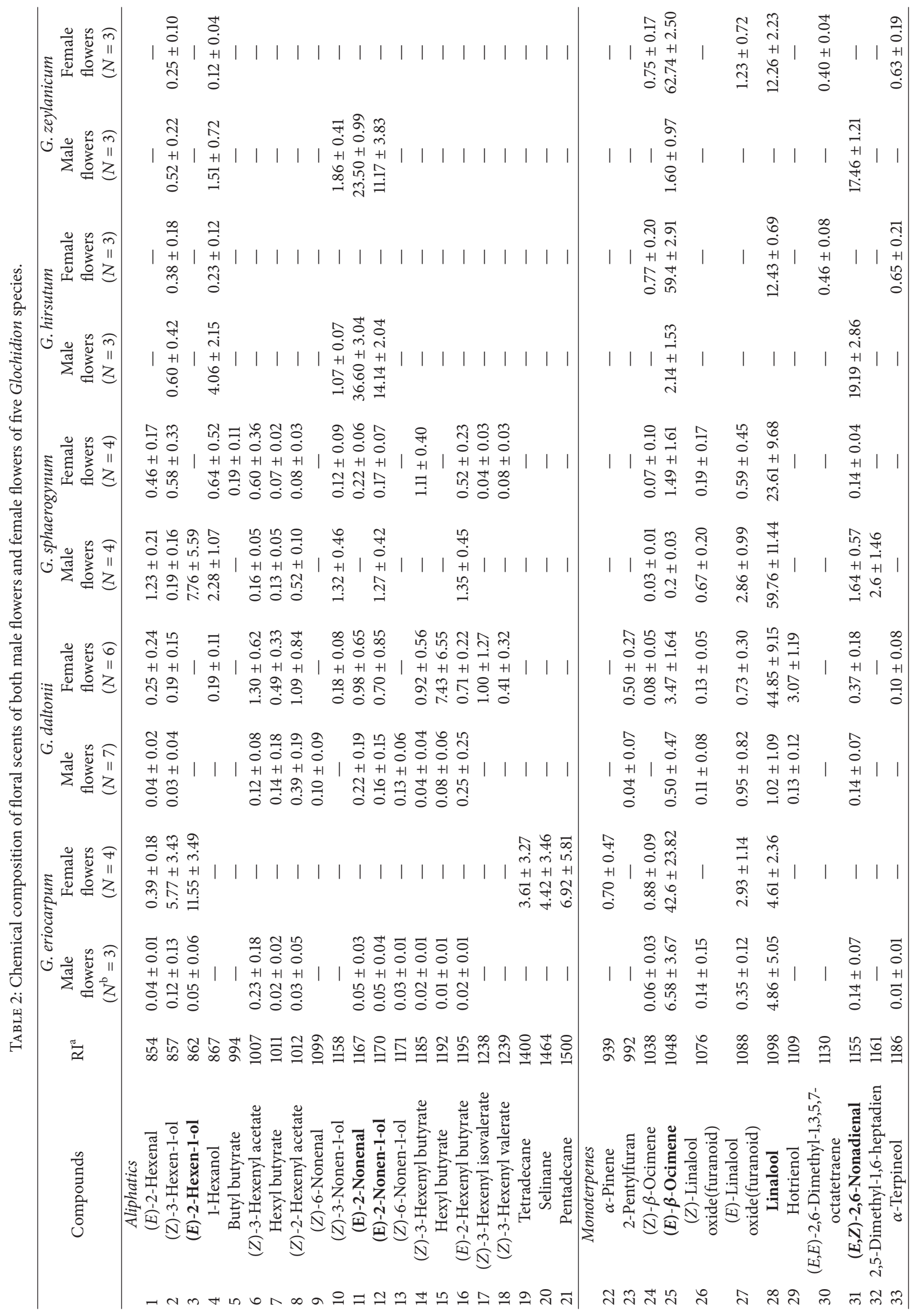




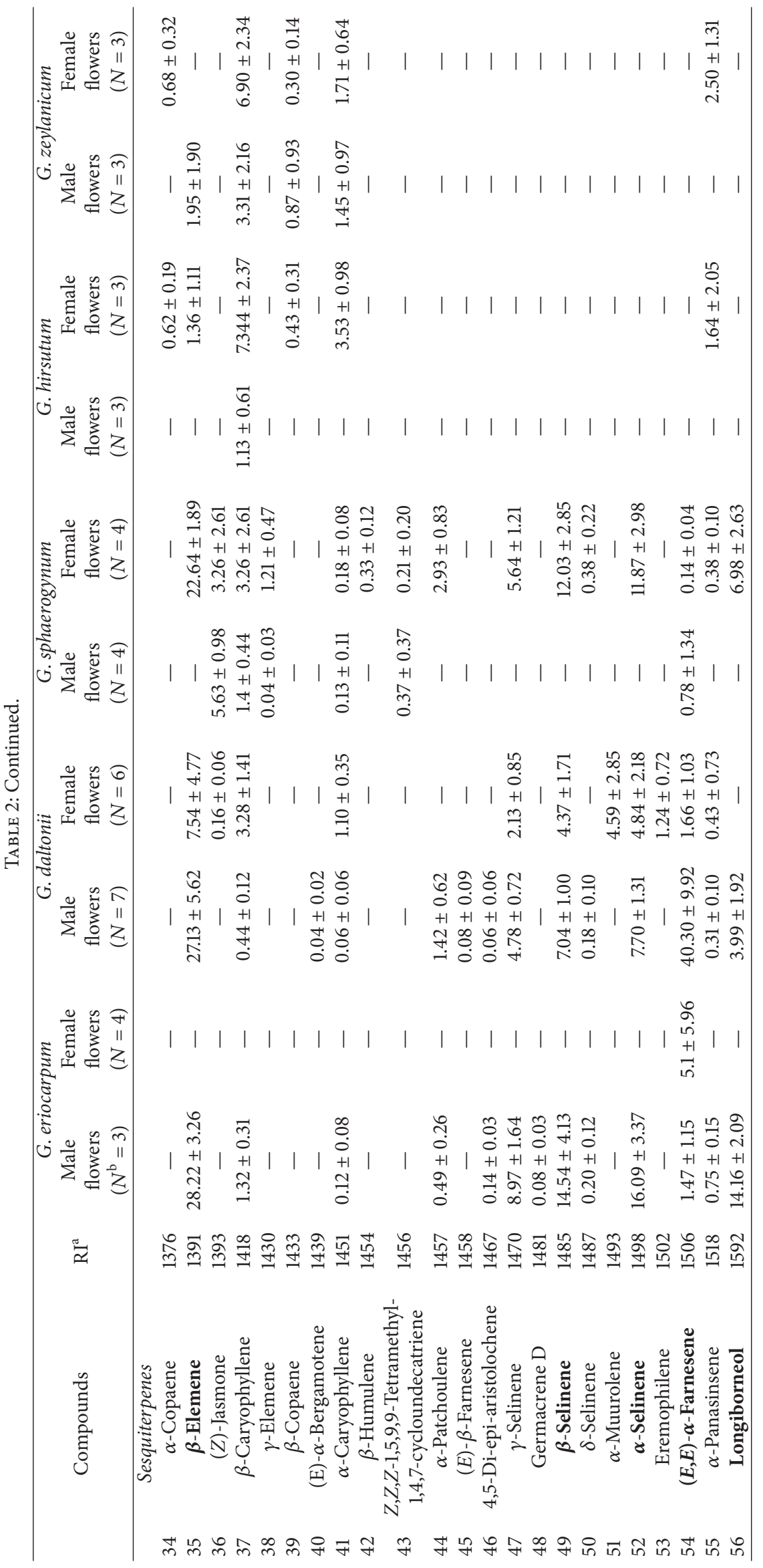




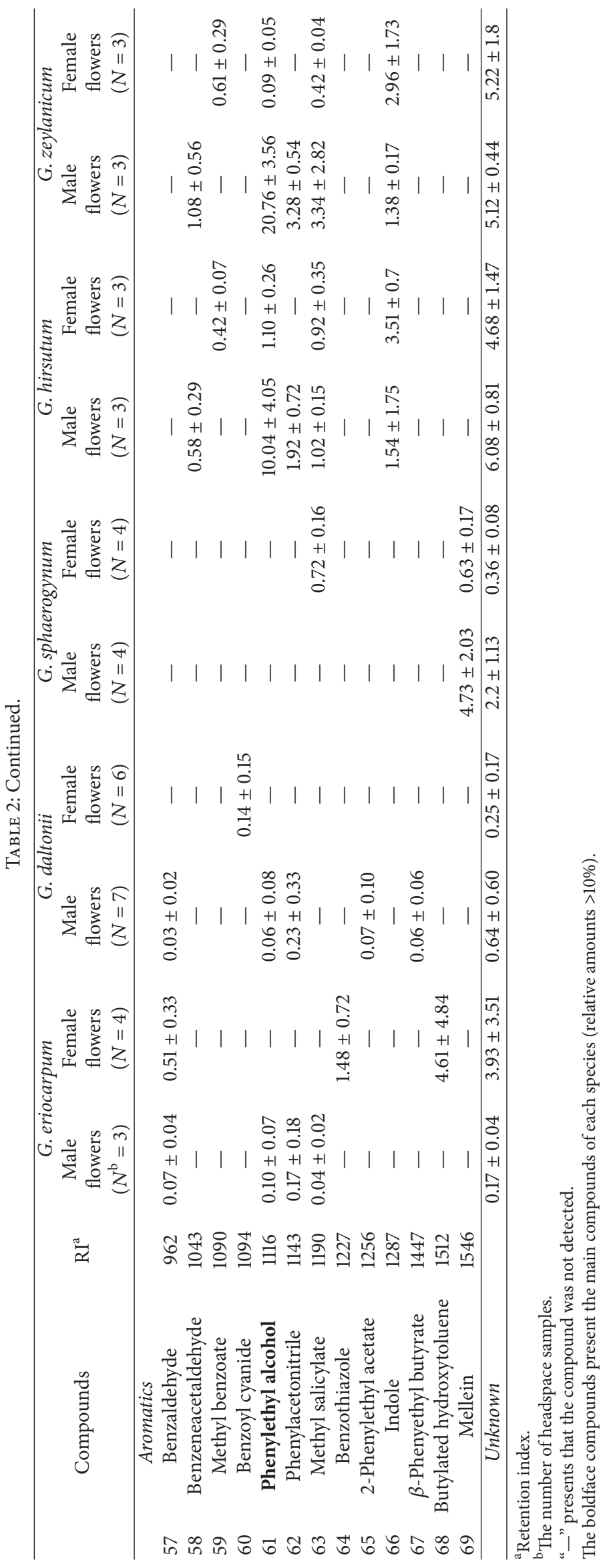




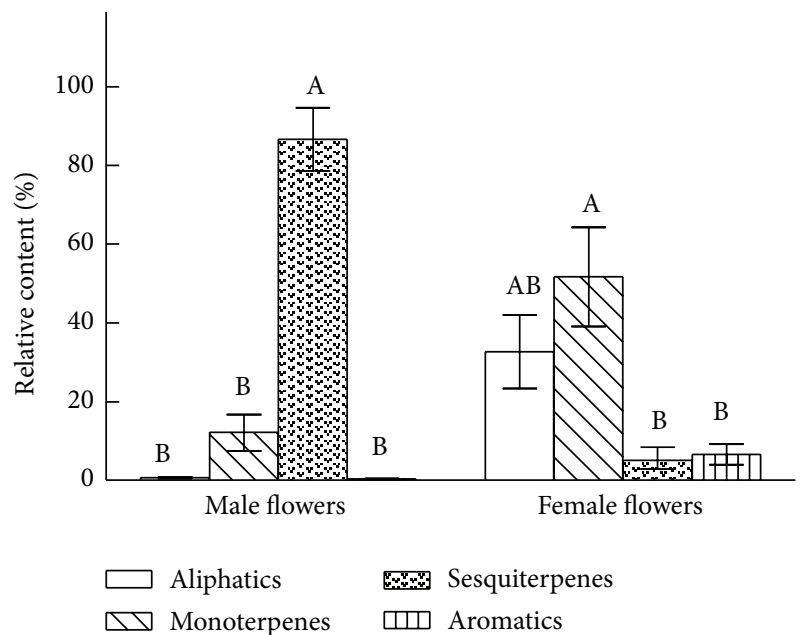

(a)

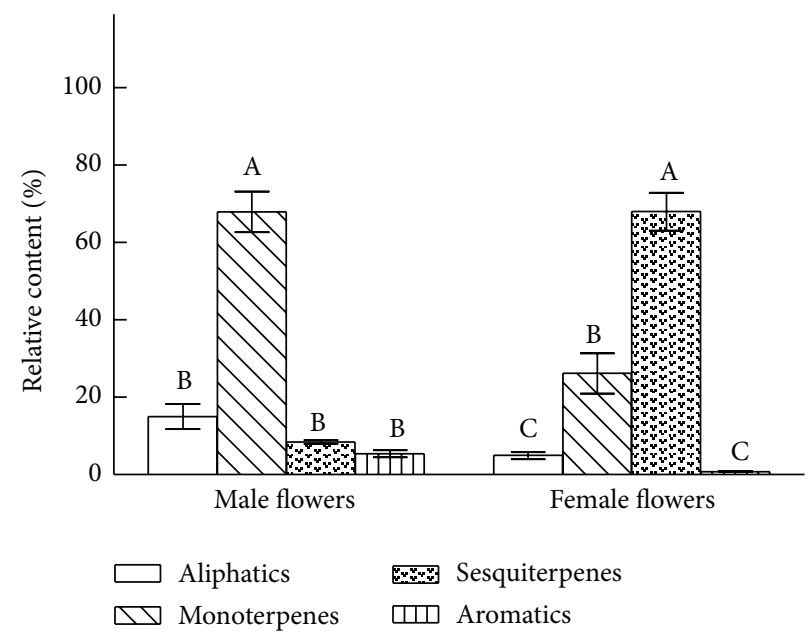

(c)

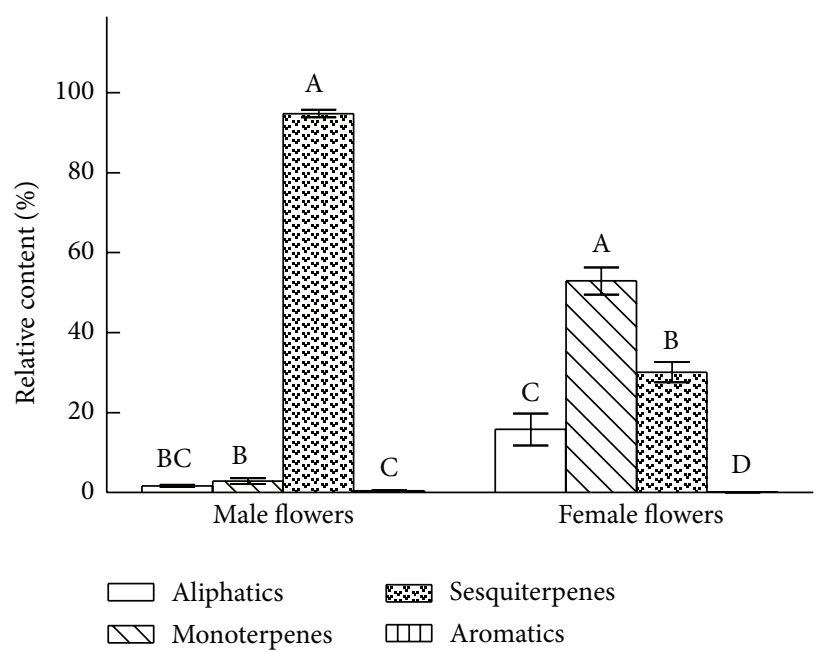

(b)

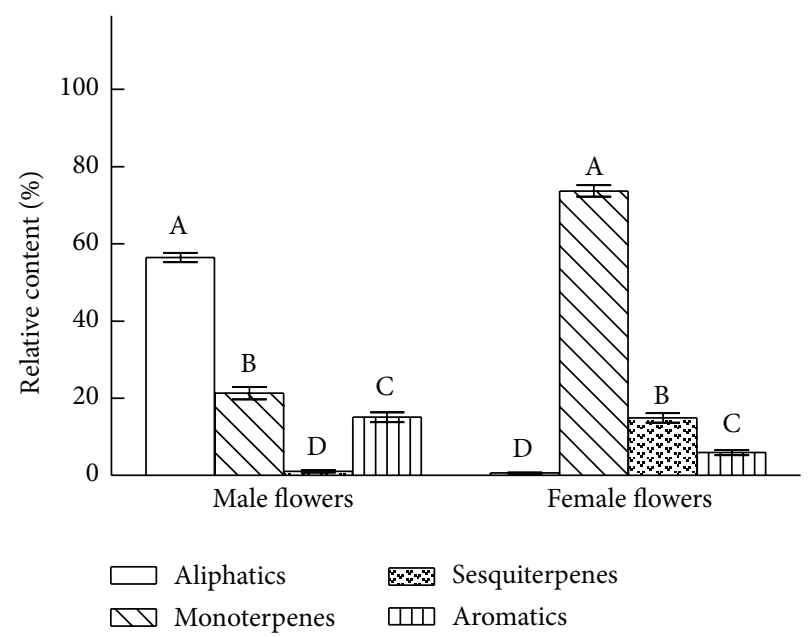

(d)

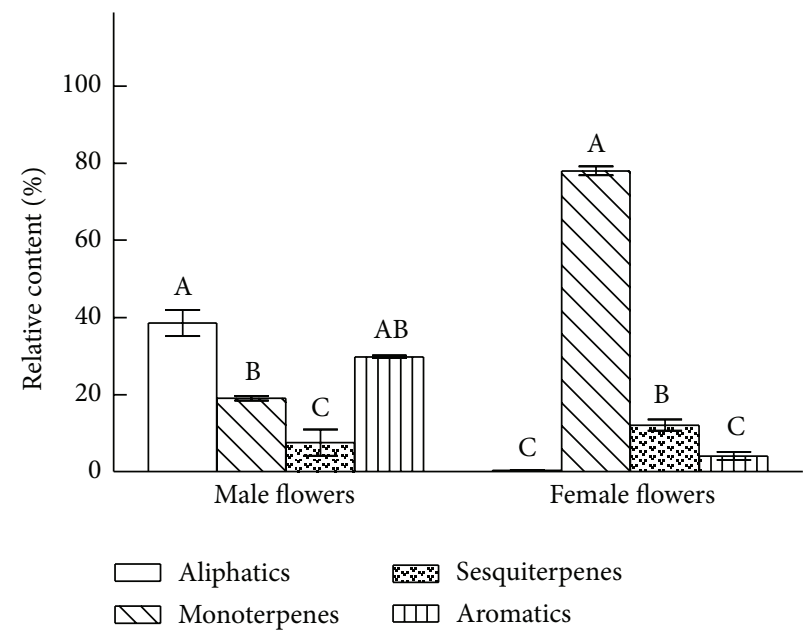

(e)

FIGURE 3: Relative amounts (\%) of four chemical classes volatile compound of both male and female flowers from five Glochidion species. (a) G. eriocarpum; (b) G. daltonii; (c) G. sphaerogynum; (d) G. hirsutum; (e) G. zeylanicum (one-way ANOVA: the different lowercase letters on the bars indicate significant difference at $P=0.05$ level). 

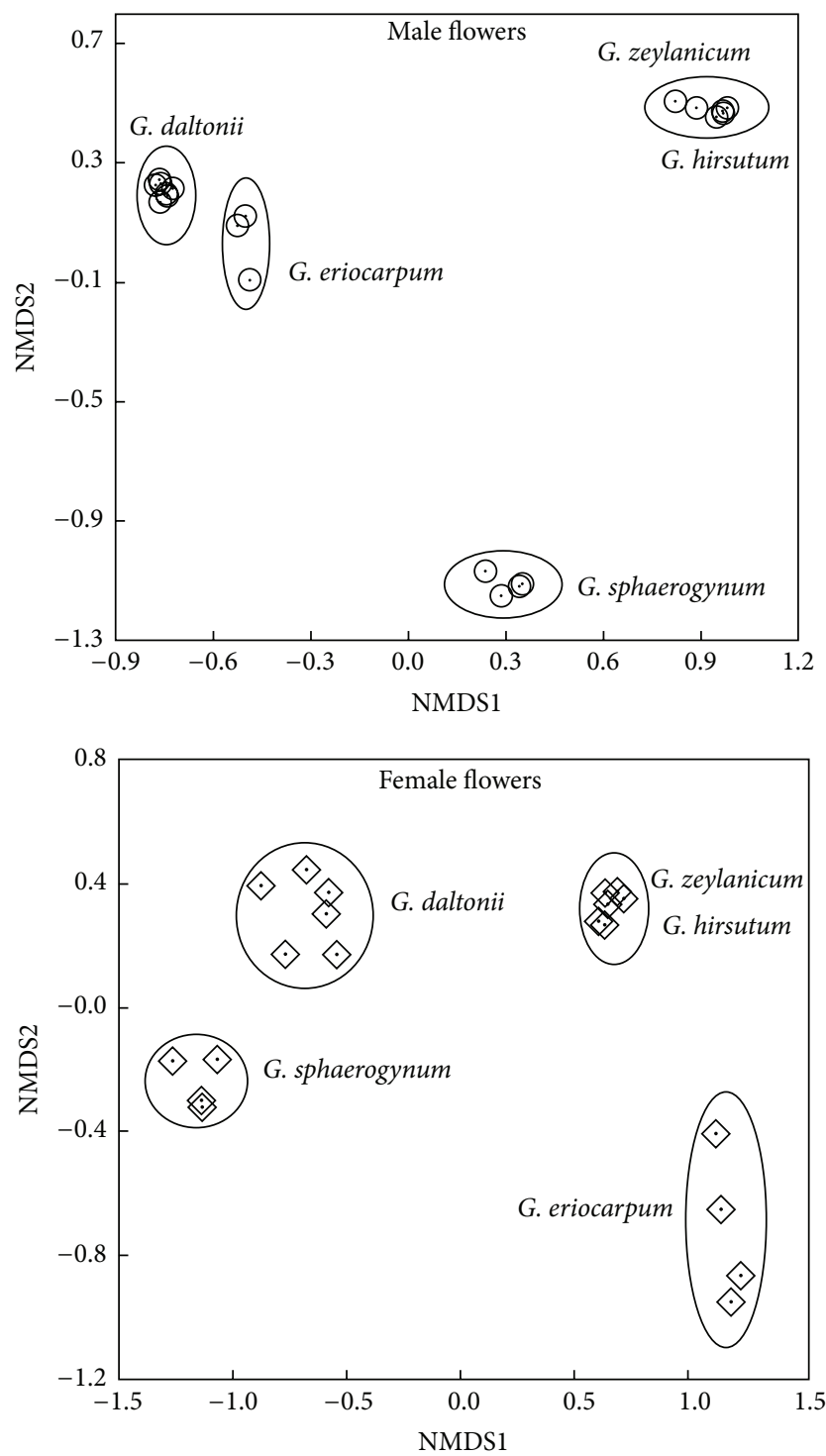

FIGURE 4: Score plots from nonmetric multidimensional scaling (NMDS) of floral scents in male and female flowers of five Glochidion species.

the results showed evident quantitative differences in floral scents between male and female flowers of the Glochidion species.

3.4. Sexual Dimorphism of Floral Scents. The NMDS analysis of floral scents in male and female flowers of each Glochidion species is shown in Figure 6. In each investigated Glochidion species, the headspace samples of male flowers were clearly separated from those of female flowers (G. daltonii: $\chi^{2}=6$, $P=0.034$; G. eriocarpum: $\chi^{2}=9, P=0.03$; G. sphaerogynum: $\chi^{2}=5.33, P=0.021 ; G$. hirsutum and G. zeylanicum: $\left.\chi^{2}=3.857, P=0.05\right)$. The results indicated a qualitative difference between floral scents produced by male and female Glochidion flowers, which is so-called sexual dimorphism of floral scents.

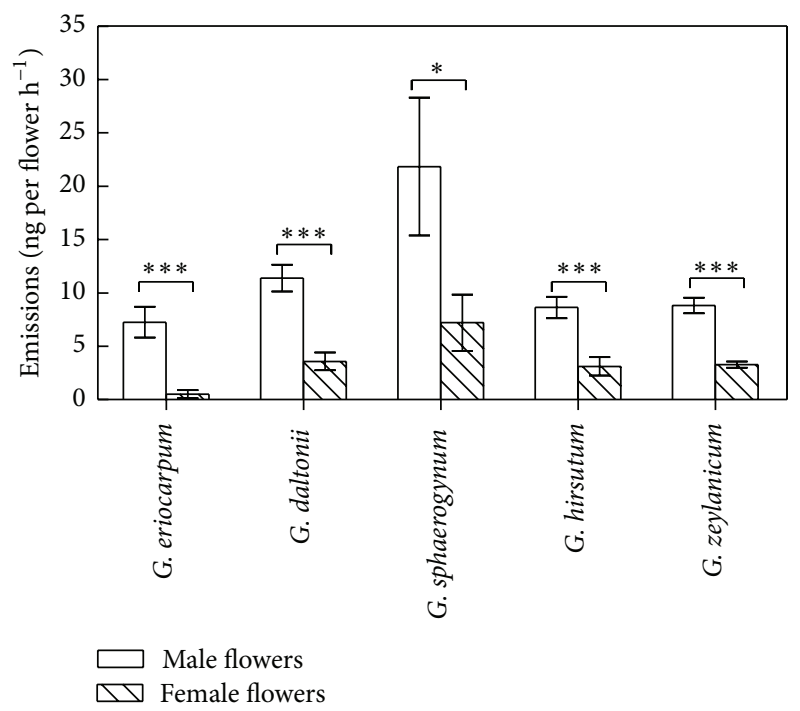

FIgUre 5: Total emission (Mean \pm SD) of scent compounds from male and female flowers of five Glochidion species (unpaired $t$-test: “*” and “***" on the bars indicate significant difference at $P=0.05$ and 0.001 level).

\section{Discussion}

In total, 69 volatiles are detected from the floral scents of the five Glochidion species. Most of these reported volatiles are quite common in floral odors of many flowering plants $[33,34]$. In particular, 26 compounds also occur in floral fragrances of other Phyllantheae species, close relatives of the investigated Glochidion species, which are also exclusively pollinated by Epicephala moths [16, 18, 35]. For instance, (E)- $\beta$-ocimene (compound 25) and linalool (compound 28) occurred together in the five studied Glochidion species and are also produced by the flowers of four other reported Glochidion species $[16,18]$. In addition, these two compounds can attract a wide range of pollinators of flowering plants, such as moths [35, 36], butterflies [37], and bees [38]. Therefore, our results suggest that these interactions between Glochidion species and Epicephala moths may be mediated by conventional floral compounds. This is similar to findings in most obligate insect-plant mutualism, where identified floral volatiles are also regarded as general floral volatiles $[16,25,39]$. However, Chen et al. [40] showed that an unusual compound, 4-methylanisole, mediated the species specificity in Ficus semicordata and Ceratosolen gravelyi wasp mutualism through a "private channel."

In highly specific plant-insect interactions, the floral scent profile of host plants is sometimes dominated by one or few compounds [16, 39, 41, 42], and these dominant compounds may account for variation in floral scents among species [16]. Similarly, our GC-MS showed the floral odor of each of the five species was also dominated by one compound at least, such as, for male flowers, $\beta$-elemene (compound $35,28.22 \%)$ in $G$. eriocarpum, $(E, E)-\alpha$-farnesene (compound $54,40.3 \%$ ) in $G$. daltonii, linalool (compound $28,59.75 \%$ ) in G. sphaerogynum, and (E)-2-nonenal in G. hirsutum and $G$. zeylanicum (compound 11, 36.6 and $23.5 \%$, resp.). The PCA 

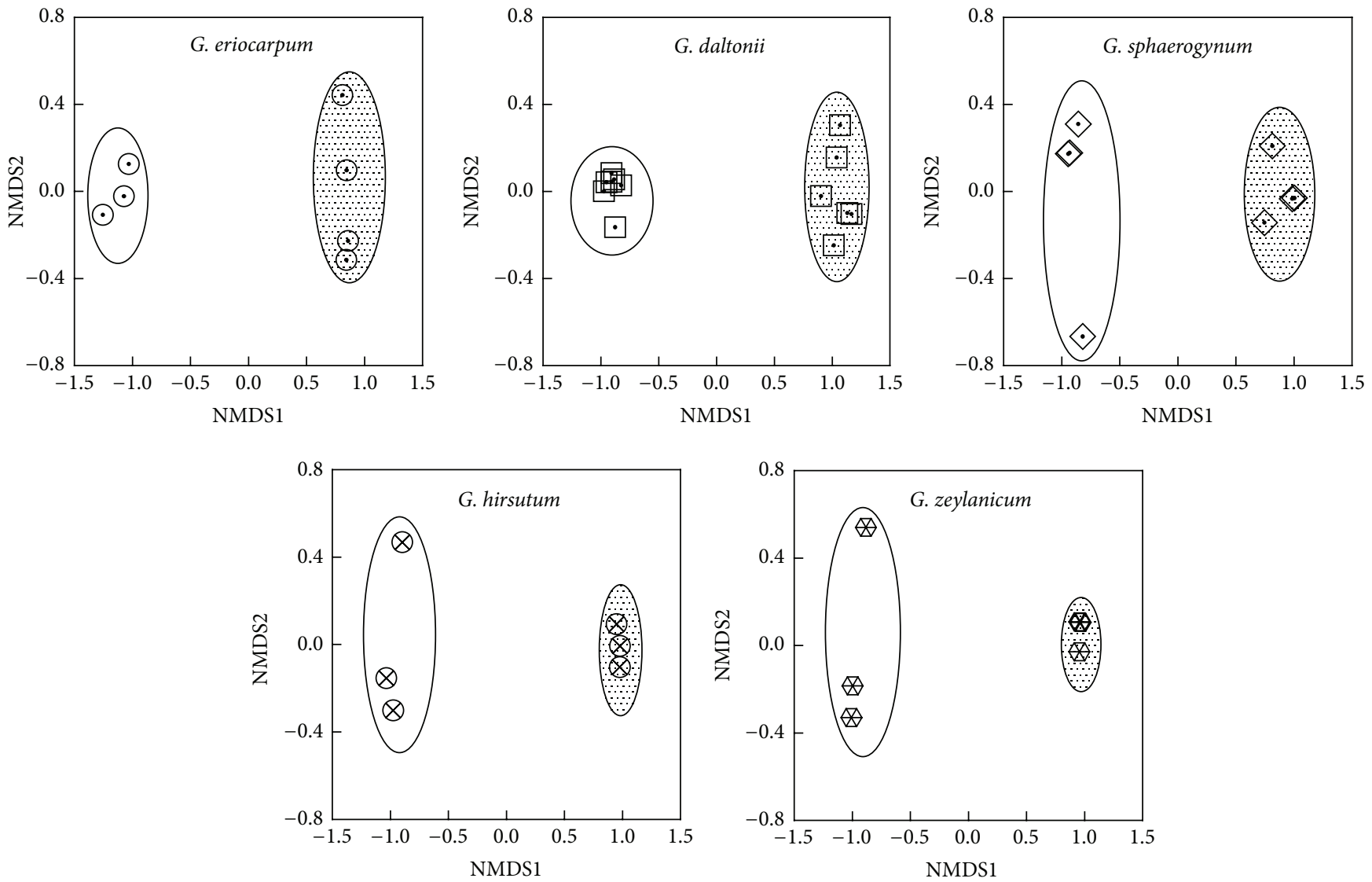

FIGURE 6: Score plots from NMDS of floral scents in male and female flowers of five Glochidion species. The headspace samples with each species are represented by different numbers sharp symbols as shown. The headspace samples within each species are boxed and coloured white for male flowers but grey for female flowers.

results revealed that both male and female flowers of the five species could be divided into four distinct groups: $G$. zeylanicum and G. hirsutum clustered together and the other species were spaced with each other. Thus, floral odors of investigated Glochidion species could be clearly discriminated mainly due to the dominant compounds. This is in contrast to findings for the odor profile of five other Glochidion species that were distinguished by minor compounds [16]. These results suggest that the presence of dominant compounds in floral scents of Glochidion species may be crucial for attracting specific Epicephala pollinators. However, electroantennographic detection analysis and behavioral tests with authentic chemicals are needed for further screening of specific compounds responsible for this host specificity.

Highly interspecific variation in floral scent has been observed in many plant species $[16,39,43-50]$. It is likely that variation in floral odor composition between species is due to adaptation to host-specific pollinators $[16,50]$. The species specificity in the Glochidion-Epicephala mutualism is extremely high, where each host plant is usually exclusively pollinated by specific pollinator species. Thus, to facilitate host specificity in these interactions, the floral scent should be selected to be strongly divergent among species. Interspecific variation in floral scent profile of Glochidion species observed in this study could contribute to the maintenance of the species specificity of the mutualism and may reflect adaptation to specific Epicephala moths. Pollinators can also find and locate their hosts by discriminating the difference in floral odor among species [16, 40]. Our NMDS analysis showed a similar floral scent profile between G. hirsutum and G. zeylanicum. In Glochidion-Epicephala mutualism, E. bipollenella moths jointly pollinated G. hirsutum and G. zeylanicum [20]. Similarly, G. obovatum and G. rubrum, two parapatric species pollinated jointly by the same Epicephala species, produced similar floral scents, more similar than those emitted by other cooccurring Glochidion species pollinated by other Epicephala species [16]. In addition, Ficus natalensis and F. burkei jointly sharing the same pollinator wasp species emitted similar floral scent profiles, which are different from those produced by other African Ficus species [51]. When different plant species are pollinated by the same group of pollinators and especially by closely related pollinator taxa, they may be expected to have floral volatiles of similar chemical composition [43]. This implies that the similarity in odor of different Glochidion species in this study may suggest evolutionary convergence to attract the same Epicephala pollinators [51].

Generally, but not always, the animal-pollinated dioecious plants produce similar floral signals between male and female flowers. This is because attraction of the same 
pollinator to flowers of both sexes is essential for successful conspecific pollen transfer; thus the hosts should be selected to transmit such similar floral scents in the flowers of both sexes [21-23]. Underlying the fact above is that pollinators use similar cues to find the same floral rewards (e.g., floral nectar) from male and female flowers $[21,24]$. Selection for similarity in signals from male and female flowers is thought to be particularly strong when one sex (often the female) does not produce any reward and effectively mimics flowers of the other sex, so deceptive pollination occurs in the female [52]. For instance, chemical mimicry in floral scent occurs in fig-fig-wasp highly species-specific pollination systems. Although fig wasps are deceived into pollinating female figs but do not obtain any reward from female figs, the pollinated female figs can produce seeds to ensure the successful reproduction of fig species. Therefore, for fig-fig-wasp attraction, selection for chemical mimicry between sexes is suggested to be particularly critical to maintain the stability of obligate pollination mutualism between fig and fig wasp [40, 52, 53]. In addition, chemical mimicry between sexes of the flowers has also been documented in cycad species [50, 54-57]. Hemborg and Bond [24] proposed that different rewards offered by male and female flowers of some plant species to pollinators could promote the evolution of sexually dimorphic floral signals of flowers. Svensson et al. [25] and Okamoto et al. [18] found that Epicephala-pollinated Phyllanthaceae plants consistently showed clear differences in scent between male and female flowers. Similarly, our NMDS results also revealed in Glochidion-Epicephala a remarkable sexual dimorphism in floral scent between sexes of the five investigated Glochidion species. In Epicephala-pollinated Phyllanthaceae, when Epicephala moths pollinate for the host, male flowers can offer pollen to pollinators as food, whereas female flowers can provide the ovule for Epicephala adults as egg-laying sites and seeds for Epicephala larvae as foods [5, 9-12], and it was thought that Epicephala moths could get access the different and essential rewards from the flowers of both sexes of hosts; thus sexual dimorphism in floral scent of two sexes in Epicephala-pollinated Phyllanthaceae is selected to signal an alternative reward provided by each sex to Epicephala moths. Epicephala can also distinguish male and female flowers by odor and is crucial for successful reproduction of the moths and plants [18]. Our results also provide strong support that different rewards in male and female flowers result in the sexual dimorphism in floral scent of flowers of Glochidion species in this study [24].

Our results showed quantitative differences in floral scent emission between the sexes in each studied Glochidion species. In addition, there was a similar finding for $B$. vitisidaea, a close relative of Glochidion, which is also obligately pollinated by species-specific Epicephala moths [25]. Okamoto et al. [18] showed that Epicephala moths preferred the scent of male flowers over that of female flowers in $G$. zeylanicum. According to sexual selection theory, the males are limited in their reproductive success by access to mates, while females are mostly limited by available resources [58]. In animal-pollinated plants, attraction of pollinators and successful pollination are crucial for reproductive success; thus males in monoecious plants are expected to be under selection to increase their attractiveness to pollinators by investing more than females in floral traits that enhance pollinator visitation. Generally, male plants should produce more floral scent than the females to increase pollinator attraction. Waelti et al. [59] suggested that, in the Silene latifolia-Hadena bicruris nursery pollination system, male flowers emitted significantly more fragrance, especially of the pollinator-attracting compounds, than female flowers, and pollinator-moths preferred male over female flowers in behavioral tests, implying that evolution of the divergence in the floral signal of S. latifolia is shaped by sexual selection. Ashman et al. [60] also showed that the smaller hermaphroditic flowers in the gynodioecious strawberry Fragaria virginiana produced larger amounts of foliage volatiles, which resulted in attraction of more pollinators compared to female flowers. Therefore, more probably, the observed quantitative difference in floral scent of flowers between the sexes in the five species of Glochidion may be an outcome of sexual selection. It is possible that the stronger odor emission of male flowers in Glochidion species resulted in increasing attractiveness for Epicephala moths compared with female flowers.

\section{Conclusions}

Our findings suggest that the volatile variation of floral scent among Glochidion species reflects adaptations to specific pollinators. Sexual dimorphism in floral scent has evolved to signal alternative rewards provided by each sex to Epicephala moths. It is concluded that floral scent has been thought to play key role in the obligate pollination mutualism between Glochidion plants and Epicephala moths.

\section{Conflict of Interests}

The authors declare that there is no conflict of interests regarding the publication of this paper.

\section{Acknowledgments}

The authors appreciate Zongbo Li for technical help in scent collection and GC-MS analysis. They also are grateful to Zhibo Wang, Zhenguo Zhang, Xiaofei Yang, and Guoping Chen for dedicated assistance in the field work. Special thanks are given to members of Tianzhu Mountain National Forest Park, Yingge Mountain Nature Reserves and Tropical Forestry Experiment Center, and Chinese Academy of Forestry Sciences for logistic support and kind help during their field work. This research was supported by the National Natural Science Foundation of China (no. 30930014).

\section{References}

[1] J. L. Bronstein, R. Alarcón, and M. Geber, "The evolution of plant-insect mutualisms," New Phytologist, vol. 172, no. 3, pp. 412-428, 2006.

[2] J. L. Bronstein, W. G. Wilson, and W. F. Morris, "Ecological dynamics of mutualist/antagonist communities," The American Naturalist, vol. 162, no. 4, pp. S24-S39, 2003. 
[3] D. H. Janzen, "How many babies do figs pay for babies?" Biotropica, vol. 11, no. 1, pp. 48-50, 1979.

[4] G. D. Weiblen, "How to be a fig wasp," Annual Review of Entomology, vol. 47, pp. 299-330, 2002.

[5] M. Kato, A. Takimura, and A. Kawakita, "An obligate pollination mutualism and reciprocal diversification in the tree genus Glochidion (Euphorbiaceae)," Proceedings of the National Academy of Sciences of the United States of America, vol. 100, no. 9, pp. 5264-5267, 2003.

[6] O. Pellmyr, "Yuccas, yucca moths, and coevolution: a review," Annals of the Missouri Botanical Garden, vol. 90, no. 1, pp. 3555, 2003.

[7] M. Dufaÿ and M.-C. Anstett, "Conflicts between plants and pollinators that reproduce within inflorescences: evolutionary variations on a theme," Oikos, vol. 100, no. 1, pp. 3-14, 2003.

[8] A. Biere and S. C. Honders, "Coping with third parties in a nursery pollination mutualism: Hadena bicruris avoids oviposition on pathogen-infected, less rewarding Silene latifolia," New Phytologist, vol. 169, no. 4, pp. 719-727, 2006.

[9] A. Kawakita and M. Kato, "Evolution of obligate pollination mutualism in New Caledonian Phyllanthus (Euphorbiaceae)," American Journal of Botany, vol. 91, no. 3, pp. 410-415, 2004.

[10] A. Kawakita and M. Kato, "Obligate pollination mutualism in Breynia (Phyllanthaceae): Further documentation of pollination mutualism involving Epicephala moths (Gracillariidae)," American Journal of Botany, vol. 91, no. 9, pp. 1319-1325, 2004.

[11] J. Zhang, S. X. Wang, H. H. Li, B. B. Hu, X. F. Yang, and Z. B. Wang, "Diffuse coevolution between two Epicephala species (Gracillariidae) and two Breynia species (Phyllanthaceae)," PLoS ONE, vol. 7, no. 7, Article ID e41657, 2012.

[12] R. Govaerts, D. G. Fronding, and A. Randcliffe-Smith, World Checklist and Bibliography of Euphorbiaceae, Royal Botanic Gardens, Kew, UK, 2000.

[13] B. T. Li, H. X. Qiu, J. S. Ma et al., "Euphorbiaceae," in Flora of China, Z. Y. Wu, P. H. Raven, and D. Y. Hong, Eds., vol. 11, pp. 177-209, Science Press, Missouri Botanical Garden Press, Beijing, China, 2008.

[14] A. Kawakita and M. Kato, "Assessment of the diversity and species specificity of the mutualistic association between Epicephala moths and Glochidion trees," Molecular Ecology, vol. 15, no. 12, pp. 3567-3581, 2006.

[15] D. R. Gang, "Evolution of flavors and scents," Annual Review of Plant Biology, vol. 56, pp. 301-325, 2005.

[16] T. Okamoto, A. Kawakita, and M. Kato, "Interspecific variation of floral scent composition in Glochidion and its association with host-specific pollinating seed parasite (Epicephala)," Journal of Chemical Ecology, vol. 33, no. 5, pp. 1065-1081, 2007.

[17] M. Hossaert-McKey, C. Soler, B. Schatz, and M. Proffit, "Floral scents: their roles in nursery pollination mutualisms," Chemoecology, vol. 20, no. 2, pp. 75-88, 2010.

[18] T. Okamoto, A. Kawakita, R. Goto, G. P. Svensson, and M. Kato, "Active pollination favours sexual dimorphism in floral scent," Proceedings of the Royal Society of London B, vol. 280, no. 1772, Article ID 20132280, 2013.

[19] B. B. Hu, H. H. Li, and F. C. Shi, "Advence in the study of the mutualism between Epicephala mothes (Lepidoptera, Gracillariirdae) and Euphorbiaceae plants in China," Acta Zootaxonomica Sinica, vol. 36, no. 2, pp. 447-457, 2011.

[20] J. Zhang, B. B. Hu, S. X. Wang, and H. H. Li, "Six new species of Epicephala Meyrick, 1880 (Lepidoptera: Gracillariidae) associated with Phyllanthaceae plants," Zootaxa, vol. 3275, pp. 43-54, 2012.
[21] L. Chittka and J. D. Thomson, Cognitive Ecology of Pollination Animal Behaviour and Floral Evolution, Cambridge University Press, Cambridge, UK, 2001.

[22] C. B. Fenster, W. S. Armbruster, P. Wilson, M. R. Dudash, and J. D. Thomson, "Pollination syndromes and floral specialization," Annual Review of Ecology, Evolution, and Systematics, vol. 35, pp. 375-403, 2004.

[23] T.-L. Ashman, "Sniffing out patterns of sexual dimorphism in floral scent," Functional Ecology, vol. 23, no. 5, pp. 852-862, 2009.

[24] Å. M. Hemborg and W. J. Bond, "Different rewards in female and male flowers can explain the evolution of sexual dimorphism in plants," Biological Journal of the Linnean Society, vol. 85, no. 1, pp. 97-109, 2005.

[25] G. P. Svensson, T. Okamoto, A. Kawakita, R. Goto, and M. Kato, "Chemical ecology of obligate pollination mutualisms: testing the 'private channel' hypothesis in the Breynia-Epicephala association," New Phytologist, vol. 186, no. 4, pp. 995-1004, 2010.

[26] H. H. Li, Z. B. Wang, and B. B. Hu, "Four new species of Epicephala Meyrick, 1880 (Lepidoptera, Gracillariidae) associated with two species of Glochidion (Phyllanthaceae) from Hainan Island in China," ZooKeys, vol. 508, pp. 53-67, 2015.

[27] R. A. Raguso and O. Pellmyr, "Dynamic headspace analysis of floral volatiles: a comparison of methods," Oikos, vol. 81, no. 2, pp. 238-254, 1998.

[28] M.-S. Pyun and S. Shin, "Antifungal effects of the volatile oils from Allium plants against Trichophyton species and synergism of the oils with ketoconazole," Phytomedicine, vol. 13, no. 6, pp. 394-400, 2006.

[29] S. Takaku, W. A. Haber, and W. N. Setzer, "Leaf essential oil composition of 10 species of Ocotea (Lauraceae) from Monteverde, Costa Rica," Biochemical Systematics and Ecology, vol. 35, no. 8, pp. 525-532, 2007.

[30] P. J. Linstrom and W. G. Mallard, Eds., NIST Chemistry WebBook, NIST Standard Reference Database Number 69, National Institute of Standards and Technology, Gaithersburg, Md, USA, 2012, http://webbook.nist.gov.

[31] A. M. El-Sayed, The Pherobase: Database of Insect Pheromones and Semiochemicals, 2008, http://www.pherobase.com/.

[32] P. Legendre and L. Legendre, Numerical Ecology, Elsevier Science, Amsterdam, The Netherlands, 1998.

[33] J. T. Knudsen, R. Eriksson, J. Gershenzon, and B. Ståhl, "Diversity and distribution of floral scent," The Botanical Review, vol. 72, no. 1, pp. 1-120, 2006.

[34] J. T. Knudsen, L. Tollsten, and L. G. Bergström, "Floral scentsa checklist of volatile compounds isolated by head-space techniques," Phytochemistry, vol. 33, no. 2, pp. 253-280, 1993.

[35] A. T. Makholela and J. C. Manning, "First report of moth pollination in Struthiola ciliata (Thymelaeaceae) in southern Africa," South African Journal of Botany, vol. 72, no. 4, pp. 597603, 2006.

[36] J. T. Knudsen and L. Tollsten, “Trends in floral scent chemistry in pollination syndromes: floral scent composition in mothpollinated taxa," Botanical Journal of the Linnean Society, vol. 113, no. 3, pp. 263-284, 1993.

[37] S. Andersson, L. A. A. Nilsson, I. Groth, and G. Bergström, "Floral scents in butterfly-pollinated plants: possible convergence in chemical composition," Botanical Journal of the Linnean Society, vol. 140, no. 2, pp. 129-153, 2002.

[38] A.-K. Borg-Karlson, I. Valterová, and L. A. Nilsson, "Volatile compounds from flowers of six species in the family Apiaceae: 
bouquets for different pollinators?" Phytochemistry, vol. 35, no. 1, pp. 111-119, 1993.

[39] L. Grison-Pigé, M. Hossaert-McKey, J. M. Greeff, and J.-M. Bessière, "Fig volatile compounds-a first comparative study," Phytochemistry, vol. 61, no. 1, pp. 61-71, 2002.

[40] C. Chen, Q. Song, M. Proffit, J.-M. Bessière, Z. Li, and M. Hossaert-Mckey, "Private channel: a single unusual compound assures specific pollinator attraction in Ficus semicordata," Functional Ecology, vol. 23, no. 5, pp. 941-950, 2009.

[41] I. Terry, G. H. Walter, C. Moore, R. Roemer, and C. Hull, "Odormediated push-pull pollination in cycads," Science, vol. 318, no. 5847, p. 70, 2007.

[42] I. Terry, G. H. Walter, C. Hull, and C. Moore, "Responses of pollinating thrips and weevils to specific Macrozamia cycad cone volatiles," in Proceedings of the 7th International Conference on Cycad Biology (CYCAD '05), A. P. Vovides, D. W. Stevenson, and R. Osborne, Eds., pp. 346-371, The New York Botanical Garden Press, Xalapa, Mexico, January 2005.

[43] J. T. Knudsen and L. Tollsten, "Floral scent and intrafloral scent differentiation in Moneses and Pyrola (Pyrolaceae)," Plant Systematics and Evolution, vol. 177, no. 1-2, pp. 81-91, 1991.

[44] T. J. Barkman, J. H. Beaman, and D. A. Gage, "Floral fragrance variation in Cypripedium: implications for evolutionary and ecological studies," Phytochemistry, vol. 44, no. 5, pp. 875-882, 1997.

[45] H. E. M. Dobson, J. Arroyo, G. Bergström, and I. Groth, "Interspecific variation in floral fragrances within the genus Narcissus (Amaryllidaceae)," Biochemical Systematics and Ecology, vol. 25, no. 8, pp. 685-706, 1997.

[46] L. Grison, A. A. Edwards, and M. Hossaert-McKey, "Interspecies variation in floral fragrances emitted by tropical Ficus species," Phytochemistry, vol. 52, no. 7, pp. 1293-1299, 1999.

[47] R. A. Levin, R. A. Raguso, and L. A. McDade, "Fragrance chemistry and pollinator affinities in Nyctaginaceae," Phytochemistry, vol. 58, no. 3, pp. 429-440, 2001.

[48] R. A. Raguso, B. O. Schlumpberger, R. L. Kaczorowski, and T. P. Holtsford, "Phylogenetic fragrance patterns in Nicotiana sections Alatae and Suaveolentes," Phytochemistry, vol. 67, no. 17, pp. 1931-1942, 2006.

[49] K. R. Goodrich and R. A. Raguso, "The olfactory component of floral display in Asimina and Deeringothamnus (Annonaceae)," New Phytologist, vol. 183, no. 2, pp. 457-469, 2009.

[50] T. N. Suinyuy, J. S. Donaldson, and S. D. Johnson, "Variation in the chemical composition of cone volatiles within the African cycad genus Encephalartos," Phytochemistry, vol. 85, pp. 82-91, 2013.

[51] A. Cornille, J. G. Underhill, A. Cruaud et al., "Floral volatiles, pollinator sharing and diversification in the fig-wasp mutualism: insights from Ficus natalensis, and its two wasp pollinators (South Africa)," Proceedings of the Royal Society of London B, vol. 279, Article ID 20111972, 2011.

[52] C. C. L. Soler, M. Proffit, J.-M. Bessière, M. Hossaert-Mckey, and B. Schatz, "Evidence for intersexual chemical mimicry in a dioecious plant," Ecology Letters, vol. 15, no. 9, pp. 978-985, 2012.

[53] A. Grafen and H. C. J. Godfray, "Vicarious selection explains some paradoxes in dioecious fig-pollinator systems," Proceedings of the Royal Society B: Biological Sciences, vol. 245, no. 1312, pp. 73-76, 1991.

[54] I. Terry, C. J. Moore, G. H. Walter et al., "Association of cone thermogenesis and volatiles with pollinator specificity in
Macrozamia cycads," Plant Systematics and Evolution, vol. 243, no. 3-4, pp. 233-247, 2004.

[55] H. Azuma and M. Kono, "Estragole (4-allylanisole) is the primary compound in volatiles emitted from the male and female cones of Cycas revoluta," Journal of Plant Research, vol. 119, no. 6, pp. 671-676, 2006.

[56] I. Terry, P. I. Forster, C. J. Moore, R. B. Roemer, and P. J. Machin, "Demographics, pollination syndrome and conservation status of Macrozamia platyrhachis (Zamiaceae), a geographically restricted Queensland cycad," Australian Journal of Botany, vol. 56, no. 4, pp. 321-332, 2008.

[57] Ş. Procheş and S. D. Johnson, "Beetle pollination of the fruitscented cones of the South African cycad Stangeria eriopus," American Journal of Botany, vol. 96, no. 9, pp. 1722-1730, 2009.

[58] A. J. Bateman, "Intra-sexual selection in Drosophila," Heredity, vol. 2, no. 3, pp. 349-368, 1948.

[59] M. O. Waelti, P. A. Page, A. Widmer, and F. P. Schiestl, "How to be an attractive male: floral dimorphism and attractiveness to pollinators in a dioecious plant," BMC Evolutionary Biology, vol. 9, article 190, 2009.

[60] T.-L. Ashman, M. Bradburn, D. H. Cole, B. H. Blaney, and R. A. Raguso, "The scent of a male: the role of floral volatiles in pollination of a gender dimorphic plant," Ecology, vol. 86, no. 8, pp. 2099-2105, 2005. 

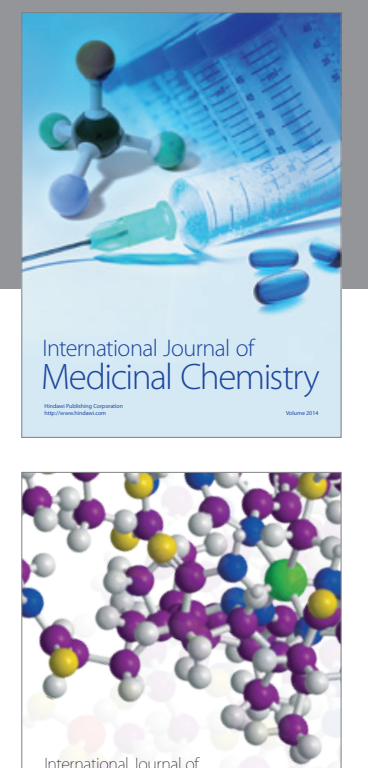

\section{Carbohydrate} Chemistry

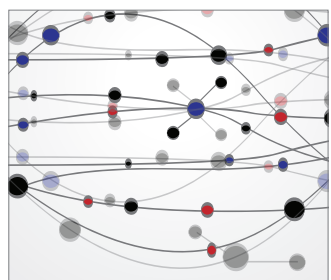

The Scientific World Journal
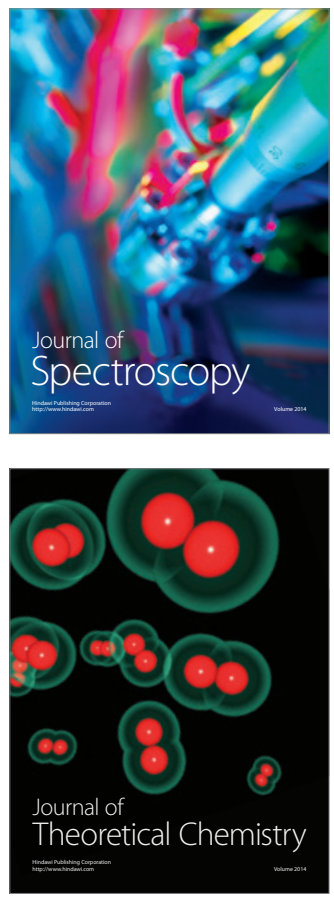
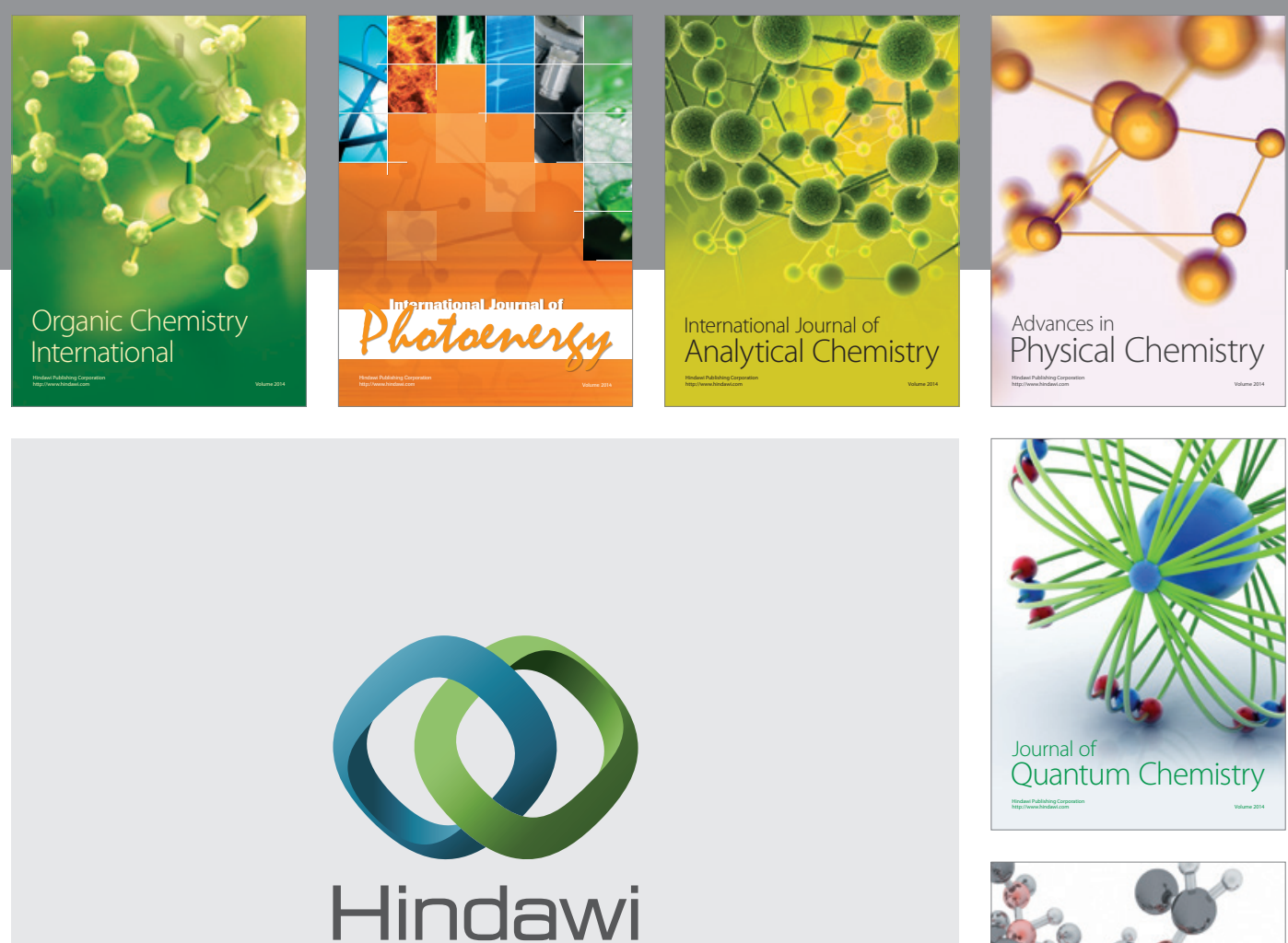

Submit your manuscripts at

http://www.hindawi.com

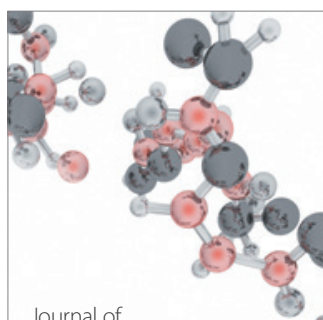

Analytical Methods

in Chemistry

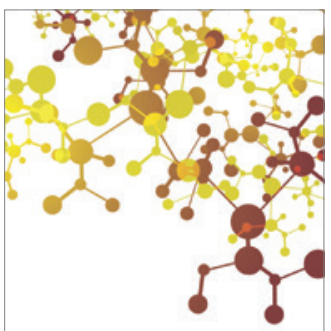

Journal of

Applied Chemistry

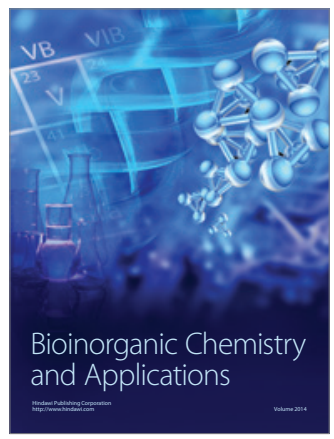

Inorganic Chemistry
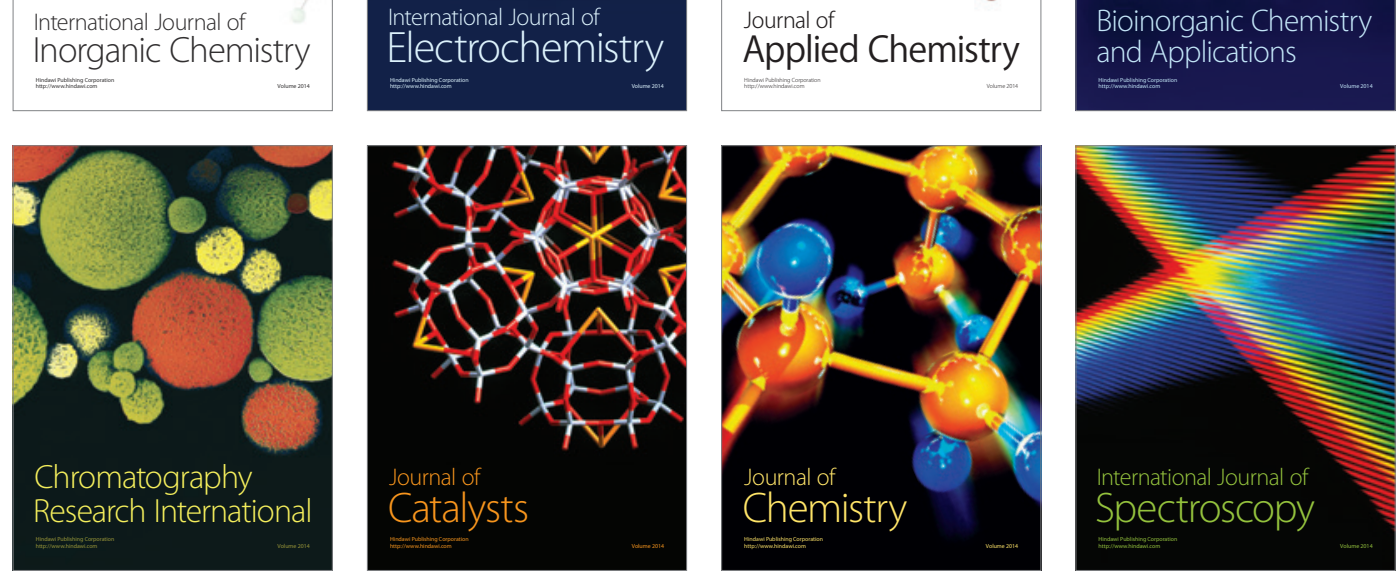